\title{
The start of the world as we know it
}

\section{Plate tectonics has created oceans and pushed up mountain ranges. But when did the process that shapes the planet get going? Alexandra Witze joins the geologists debating the issue.}

$\mathrm{O}$ $\mathrm{n}$ a sunny, breezy day in the Wind River Mountains of Wyoming, a group of geologists are peering intently at a dark ridge of rock. Some 2.7 billion years ago, these rocks were alive with volcanic fire. Today, they jut out of a mountainside like the spiny tail of a sleeping dragon.

This rock, says Kevin Chamberlain, a geologist from the University of Wyoming in Laramie, could be a special kind - a lava called a komatiite. Today, Earth's interior is too cool to produce this particular rock; 2.7 billion years ago, the hot lava would have run like water over the barren landscapes.

But as the other geologists chip off fresh layers and scrutinize them through hand lenses, murmurs of dissent start to grow. Most geologists have never seen a komatiite; they are found almost exclusively among rocks of the Archaean era, which are more than 2.5 billion years old and thus very rare. But these men and women are experts in the truly old. And on the Wyoming hillside few of them are convinced that they are seeing the rock textures typically found in komatiites.

The scene brings home the difficulties of trying to study the early Earth - there aren't many old rocks to look at, and those that are around are often so altered, chemically and physically, as to be nearly indecipherable. But as if to recompense those who study them, such ancient rocks, particularly of Archaean age, offer geologists great rewards. It is in the Archaean that the first earthly ecosystems are found, with their clues to life's earliest days on the planet. And it is in the Archaean that scientists can look for the beginnings of plate tectonics.

Plate tectonics is the grand unified theory of geology. Everything we see today, from the abyssal plains of the oceans to the heights of the Himalayas, is shaped by plate tectonics. As far back as there has been complex life - and perhaps even before - continents have come together and moved apart in a dance that has altered climates and geographies, opening up new possibilities for life and sometimes closing down old ones.

But it may not always have been so. Plate tectonics is driven by Earth's heat and constrained by the physical and chemical properties of the crust and mantle. The further back in time you go, the more different these things are likely to have been. It's been argued that on the early Earth, crustal plates, floating on a heat-softened layer of material beneath, would have simply been too thick and buoyant to get dragged beneath each other as they are today. And the greater temperature of the early Earth's innards would probably have made them move

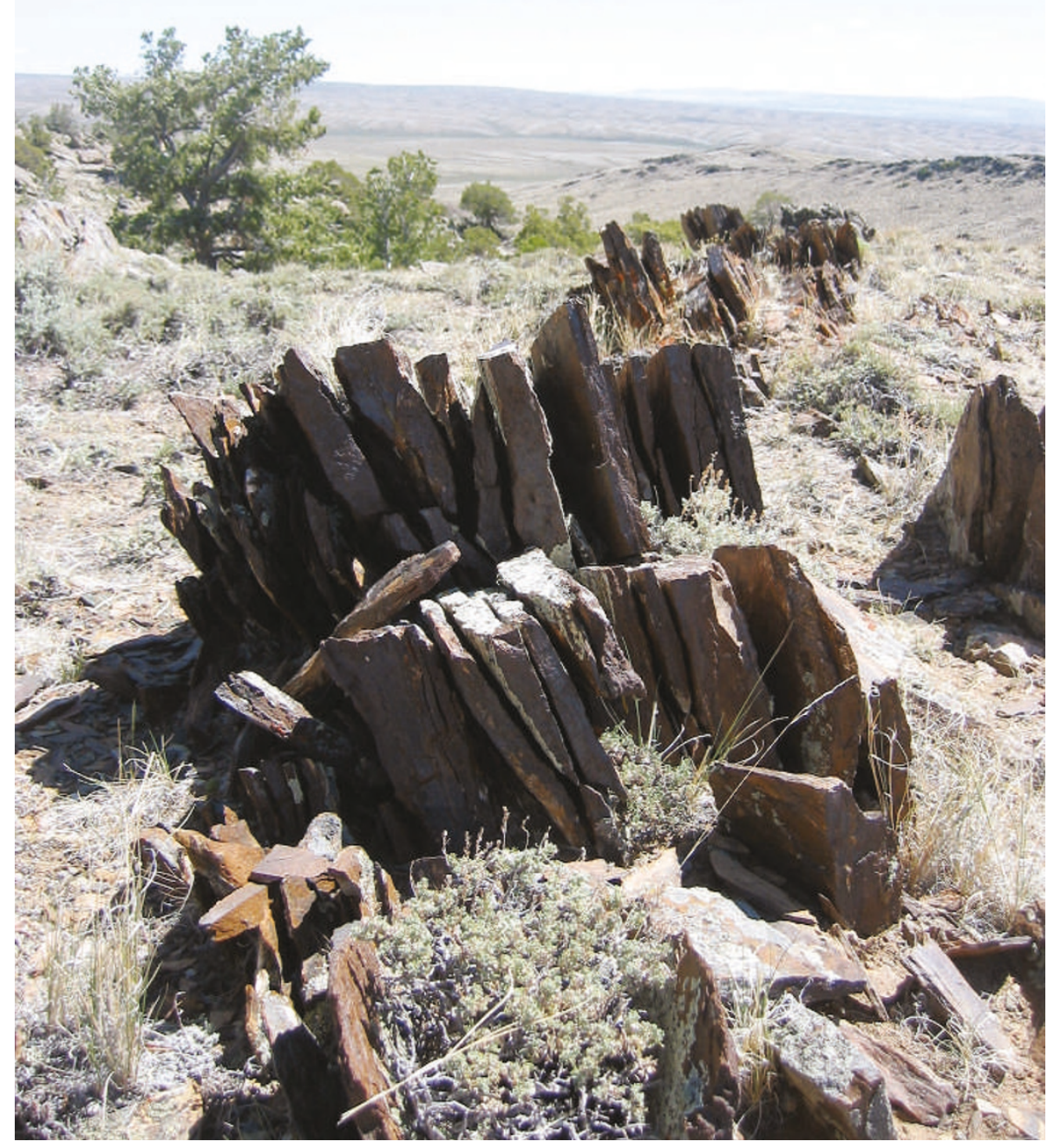

Ancient rocks, such as those in the Wind River Mountains, could help determine when plate tectonics began.

in very different patterns from those typical of today's tectonics.

On other Earth-like planets there's no evidence for today's plate tectonics. Planets do not have to work this way, and there was probably a time when this one didn't. "You don't just make a silicate planet and plate tectonics starts," says Robert Stern, a geologist at the University of Texas, Dallas. "Something special has to happen."

\section{Dynamic planet}

The nature of that special something cuts to the discipline's philosophical heart. Since the early nineteenth century, geology has been ruled by the principle of uniformitarianism that the planet operates on unchanging laws, and that the present can be used as a key to the past. But how can that approach hold up when a science from a world where plate tectonics explains more or less everything is applied to a world that may have lacked it? How can you understand ancient rocks when you do not know what processes put them there?

The geologists clustered around the possible komatiites in the Wyoming hills had gathered to discuss these questions. Their visit to the mountain ridge had been organized as part of a June conference held in Lander, Wyoming. The specific aim of the meeting was to try to fix a date for the onset of plate tectonics: the earliest possibility is pretty much straight after the planet formed, about 4.5 billion years ago; the latest is just 1 billion years ago.

To help them decide, the scientists brought to the table data from an array of disciplines. Geochemistry can help clarify the temperature and pressure at which Archaean rocks formed. Fragments of zircon crystals dated even earlier 
- to the Hadean eon, which stretches from about 3.8 billion years ago to the planet's birth - can provide hints about what Earth's surface environment was like back then. Palaeomagnetic studies can show how land masses moved across latitudes. And structural geology can identify features that, in today's world at least, seem to be indicative of plate tectonics. But in all these approaches, as with the komatiites, age makes the picture hard to discern.

\section{Crashing continents}

Scant and difficult-to-interpret evidence presents one set of problems; slippery definitions present another. Plate tectonics has lots of constituent parts. It's not just a theory of how things move, but of how they are made and from what. For example, explanations for different sorts of volcanism in different settings also explain why the mineral make-up of continental crust and the crust beneath the oceans is so different.

Working out which attributes are essential to the theory, and which incidental, is not easy. The 65 attendees at the Wyoming conference came up with 18 different definitions of plate tectonics. Three components, most agreed, were key: there must be rigid plates at the surface of the Earth; those plates must move apart through ocean spreading, with new crust being made where the sea floor pulls apart; and the plates must on occasion dive beneath each other at subduction zones (see graphic).

The problem is that Earth could display one or even two of these properties without necessarily having a system like that described by modern plate tectonics (see 'A world without tectonics'). Take rigid plates. Palaeomagnetic and other studies show that sections of Earth's crust moved relative to each other in the Archaean, just as modern crustal plates do. But ice floes on a polar sea move in the same way, points out geophysicist Don Anderson of the California Institute of Technology in Pasadena - and those ice floes aren't experiencing plate tectonics.

Of the three, it seems subduction is closest to being diagnostic of plate tectonics. Subduction is the process by which one crustal plate

slips beneath another, to be recycled into the mantle. Subduction requires rigid plates, and as it involves the destruction of crust, new crust must be created elsewhere, presumably at oceanic spreading ridges (see graphic); otherwise, continental crust would eventually disappear. Some argue that this means plate tectonics should date further back than the earliest firm evidence for subduction.

A dramatic use of this argument is that made by Stern. In a paper published last year, he took an extreme position, proposing that Earth has been free of plate tectonics for almost four-fifths of its life, with the system we

"You don't just make a silicate planet and plate tectonics starts. Something special has to happen." - Robert Stern

see today starting up only a billion years ago ${ }^{1}$. He had two lines of argument. One was that plate tectonics could not begin until Earth's crust was cool enough, and that barrier was only passed about a billion years ago. The other was that the only reliable evidence for subduction on the early planet came from a period more recent than that.

Stern points to the geological record of three types of rock. Ophiolites are distinctive sections of the ocean crust that gets mashed up, often through subduction, on the edges of continents. Stern argues that very few of these rocks are more than a billion years old. Metamorphic rocks called blueschists, produced by squeezing the basalt from which oceanic crust is made at high pressures but not very high temperatures, are being made in today's subduction zones; none, Stern says, has been found that is more than 800 million years old. And rocks from 'ultra-high-pressure terranes' of the sort produced where one plate rides over another are at most 630 million years old.

He also makes a more general point. A dramatic shift, such as the introduction of plate tectonics, must have had huge planetary consequences. And between 780 million and 580 million years ago, Stern says, there was a series of glaciations, some very extreme - giving rise to the term 'snowball Earth'. "It was a wild time of change," says Stern. "The biosphere was out of control." On the basis that dramatic effects require dramatic causes, he argues that the introduction of plate tectonics, and with it an increase in planet-cooling volcanic eruptions, might have precipitated the great glaciations.

\section{An age gone by}

After reading Stern's arguments, Alfred Kröner of the University of Mainz in Germany fired off a rebuttal. He argues that there's plenty of evidence for plate tectonics stretching back at least 3.1 billion years ${ }^{2}$ - including geochemical work, seismic images of the 'sutures' where colliding continents join and, indeed, a few ancient ophiolites. "I believe we can see these features all the way back" - possibly all through the Archaean, says Kröner.

The exchange of papers led to the Wyoming conference. "It was overdue," says Kröner. "Nobody ever talks to one another." In Wyoming, they did: palaeomagnetists clustered around a white board with field geologists; geophysicists sat down for a beer with geochemists.

Some of the newly shared data favour an early start for plate tectonics. Geoff Davies, a modeller at Australian National University in Canberra, presented work suggesting that one of the biggest stumbling blocks to an early start may have been removed. In the early 1990s, computer models created by Davies and others suggested that the crust on the early Earth would have been too thick and buoyant to get dragged down beneath another plate during subduction. But new simulations, using more sophisticated calculations, suggest that the crust may have been thinner than once thought ${ }^{3}$ - as thin as 4 kilometres or less which would be thinner than today's crust. "Maybe plate tectonics on the early Earth was viable after all," says Davies.

In other cases, recent findings overturned evidence for early plate tectonics. In 2001, a team reported that an ophiolite from Dongwanzi, China, was 2.5 billion years old - mak-

\section{THE DRIVING FORCES OF PLATE TECTONICS}

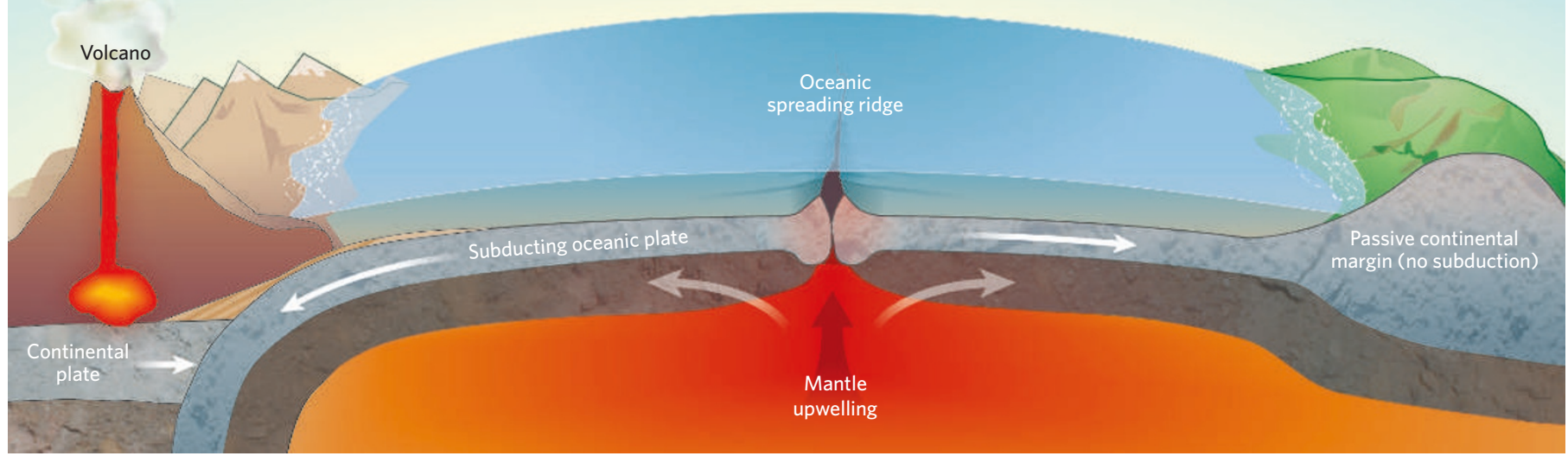




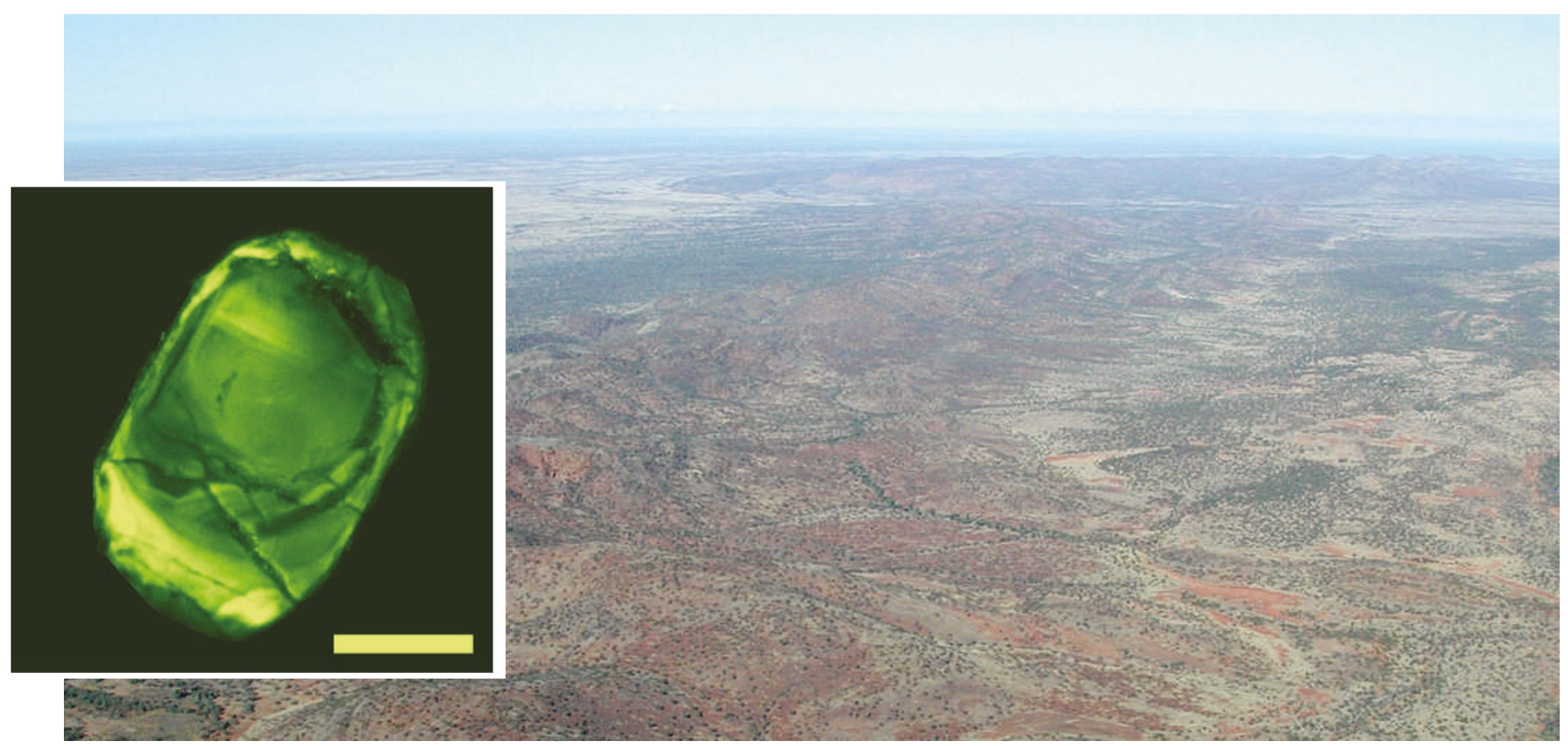

Clues to the past: zircon crystals (inset) in the Jack Hills of Western Australia have been used to argue for an early start to plate tectonics.

ing it by far the oldest such subduction remnant yet discovered ${ }^{4}$. Now Guochun Zhao, of the University of Hong Kong, has re-dated those rocks, giving them an age of just 300 million years.

Timothy Kusky of St Louis University in Missouri, who led the original study, says that Zhao took samples from a part of the rock already known to be much younger than the main part of the ophiolite. But several attendees at the meeting said they found Zhao's data convincing. If true, it would pull the earliest evidence for ophiolites at least half a billion years towards the present, leaving the Archaean an ophiolite-free zone.

The Chinese ophiolite isn't the only evi- dence that is getting fresh scrutiny. For a while two independent groups have been quietly warring over the significance of a pile of ancient zircons from the Jack Hills region of Western Australia. The zircons are crystals that formed in the Hadean and later became incorporated into younger rocks.

Last year in Science ${ }^{5}$, geochemist Mark Harrison of the University of California, Los Angeles, and colleagues used the Jack Hills zircons to argue that continental crust was present 4.4 billion to 4.5 billion years ago. The evidence comes in the form of hafnium isotope ratios in the zircon crystals, which preserve signals of the lighter minerals typical of continental crust. The data also suggest, Harrison argues, that

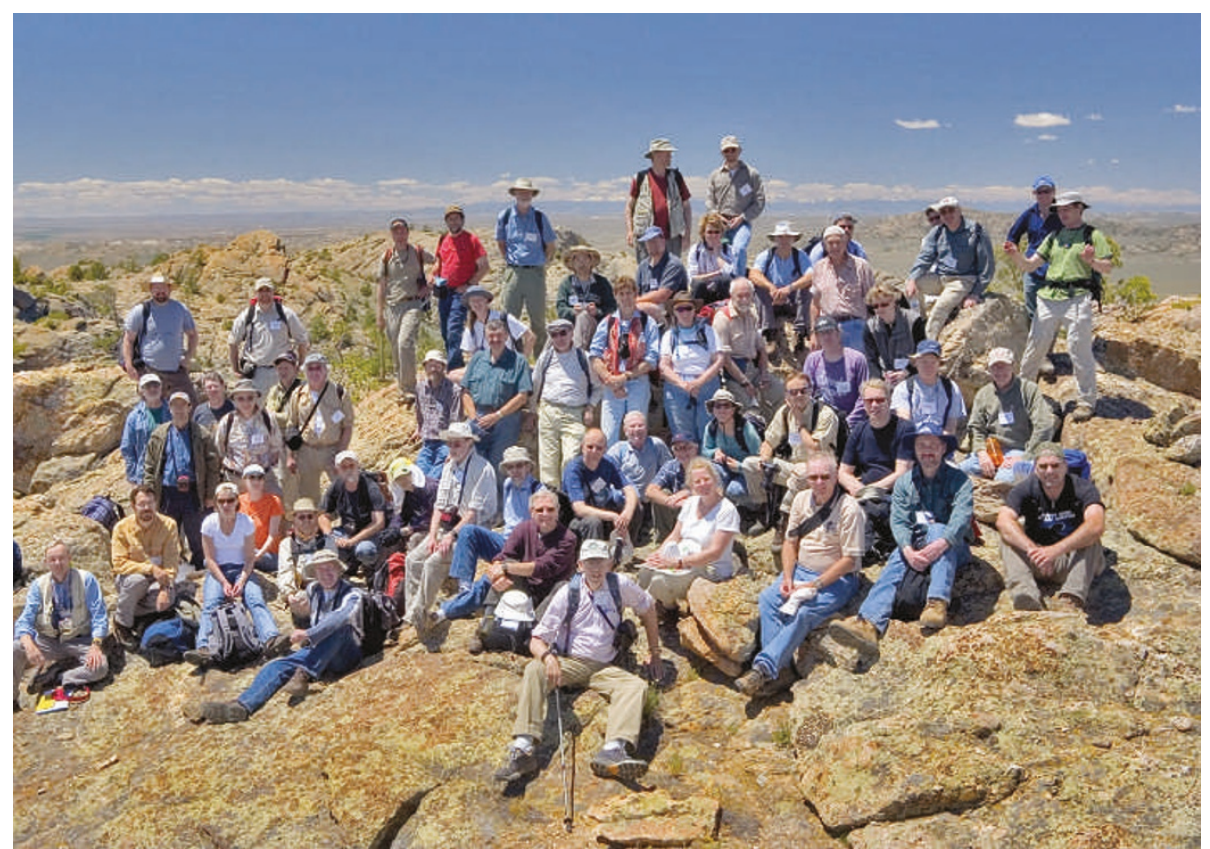

Time to talk: Earth scientists gathered at a meeting in Wyoming to present diverse data on the early Earth. that crust was being recycled down into the mantle by 4.4 billion years ago - perhaps though a process similar to plate tectonics.

Simon Wilde of the Curtin University of Technology in Perth, Australia, isn't so sure. "You have to be very careful with these rocks," he says. Measuring one spot on a crystal, as opposed to another, can yield very different hafnium values that lead to very different interpretations, he says. Wilde argues that the zircons should be interpreted more conservatively - that the evidence points to there being some continental crust, but not plate tectonics and its associated recycling, by 4.4 billion years ago ${ }^{6}$.

\section{Ground forces}

Such differences of interpretation make the problem of solving when plate tectonics began extremely difficult. In many cases, data can be interpreted in several completely different ways - all of which may seem valid.

For instance, another Australian geologist presented seemingly convincing evidence that plate tectonics had begun by 3.3 billion years ago in Western Australia, based on the very different histories of two sections of an ancient rock formation called the Pilbara. Hugh Smithies of the Geological Survey of Western Australia says that the eastern part of the Pilbara, between 3.5 billion and 3.2 billion years old, "shows no clear evidence for modern-style plate tectonics". It contains some geochemical markers that suggest subduction, but they could just as easily be explained by hot upwellings of rock known as mantle plumes or other non-tectonic phenomena.

In contrast, looking at the western part of the Pilbara - which is 3.3 billion to 3.0 billion years old - Smithies sees plenty of evidence for plate tectonics. There are geochemical signatures that cannot be explained by other factors, and the 


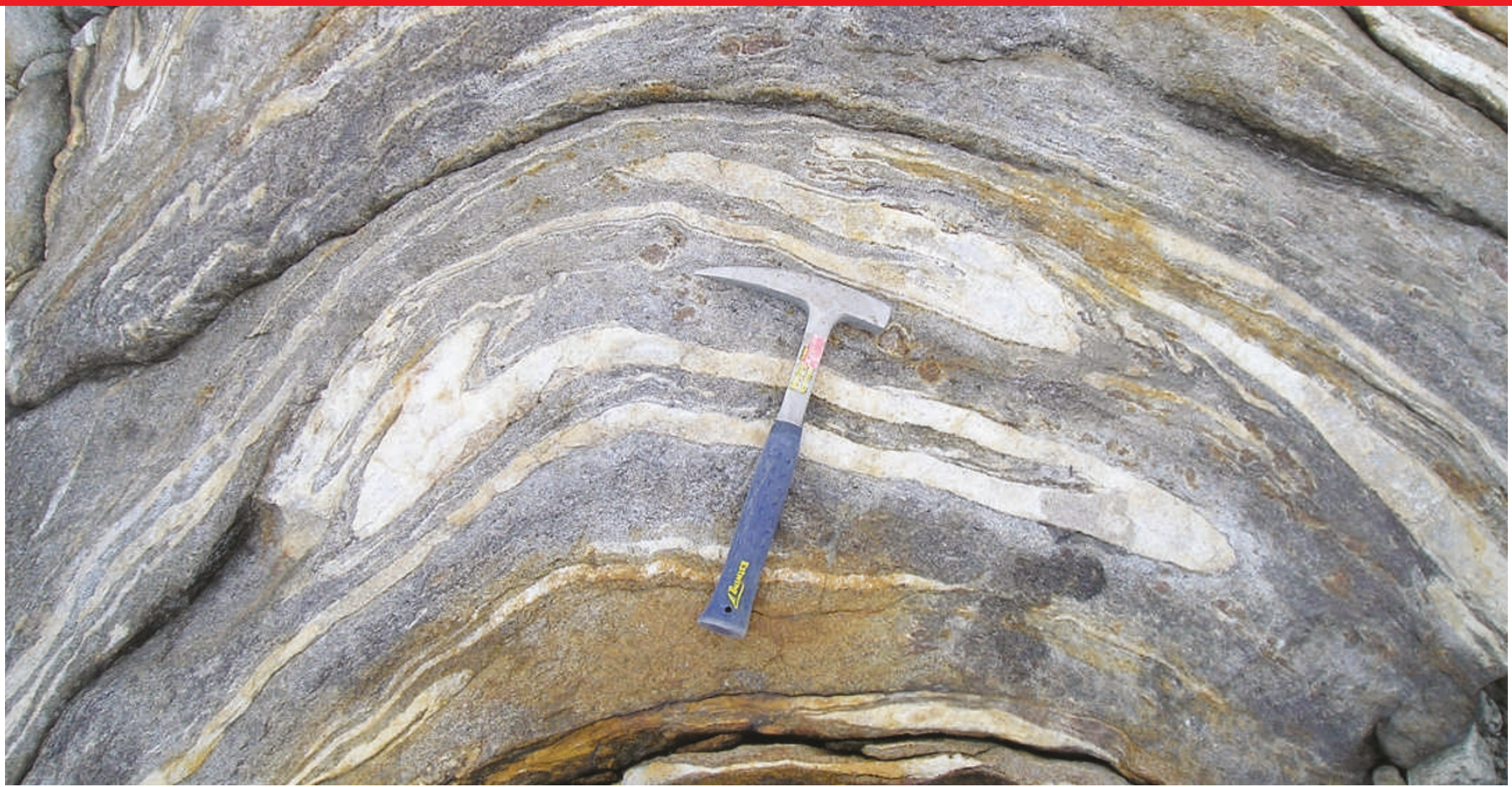

Slow work: geologists hunt for structural signatures in rocks that can only be explained by plate tectonics, to try to identify when the process started.

rocks show features that hint that plates had interacted along their edges. Smithies thinks the western Pilbara contains the remains of an oceanic arc - the sort of line of islands, such as the Aleutians of Alaska, that are characteristic of some oceanic subduction zones ${ }^{7}$.

But then along came Julian Pearce of Cardiff University in Wales, who argued that each of the geochemical markers in the western Pilbara can be explained by other phenomena,

\section{A WORLD WITHOUT TECTONICS}

With so much uncertainty over Earth's early history, not many geologists are willing to imagine entirely different ways in which the world might have worked before plate tectonics. One of the brave few is Jean Bédard, a geologist at the Geological Survey of Canada.

At a June conference held in Lander, Wyoming, Bédard presented one of the few fully worked out accounts of how a pre-platetectonic Earth might have worked. In his model, hot upwellings of rock known as mantle plumes partly melt the crust above them. This melting distills the crust, producing material from which light, continental-style crust is made.

The material left behind as the melt is creamed off - denser than it was before the distillation - then detaches itself from the crust and sinks back into the mantle. There, it would mix with more mantle material - and the whole process would start all over again?

Bédard himself admits that he has no idea if his proposal is right. But it is, he says, a detailed alternative theory to plate tectonics, and one that can be tested with further studies.

A.W such as magmas with an unusual amount of water in them, or crustal material from different places getting mixed up. The various researchers are hoping to settle the matter with a field trip. An excursion is already planned for next year, to re-examine the evidence for plate tectonics in the western Pilbara.

Field trips don't always resolve things. In the Wind River Mountains, the meeting attendees continued to argue about plate tectonics as they hiked from outcrop to outcrop. But a week of communing at the conference and under the high mountain sun brought them toward a consensus of sorts.

Meeting organizers polled the attendees twice on when they thought plate tectonics began. At the beginning of the meeting, guesses were spread over more than 3 billion years of Earth history. At the end, a closing ballot showed that many had begun to push their thinking further back into the past; a majority of attendees voted for plate tectonics having started between 3 billion and 4 billion years ago.

Kent Condie, one of the meeting organizers, calls that a success. "We've got a majority favouring a definition and approach," says Condie, of the New Mexico Institute of Mining and Technology in Socorro, New Mexico. "Sure, there will be a minority point of view."

At the conference, that minority pretty much constituted Stern. By the end of the meeting, he remained the one person voting for a start to plate tectonics at 1 billion years ago. "It's not a simple question," he maintains. And on that, at least, others agree.

Michael Brown, a geologist at the university of Maryland in College Park, doesn't endorse Stern's late start. But he does think that the nature of plate tectonics changed around that time. In a paper in press in Geology $y^{8}$, Brown suggests that there have been two styles of plate tectonics: the modern kind that we see today, and an earlier version that lasted from about 2.7 billion to 700 million years ago. Evidence for the earlier style, he says, comes from minerals that are typical of higher-temperature, lower-pressure environments; these suggest a hotter Earth where plates did not subduct beneath each other to great depths and pressures. Minerals characteristic of highpressure environments typify the later style. The properties of these minerals suggest to him that true plate tectonics, in which one plate subducts deeply beneath another, did not begin until about 700 million years ago.

And there is a possible further complication. Geophysicist Paul Silver, of the Carnegie Institution of Washington, raised the notion that plate tectonics may have started and stopped several times during Earth's history. This is also an idea that Stern is comfortable with - he uses it to explain the presence of a small number of ophiolites about 2 billion years ago.

An 'intermittent approach' would be a wonderful way to reconcile things - but it takes geology even further from the comforting realm of uniformitarianism, into a world where the most basic principles come and go in fits and starts.

\section{Alexandra Witze is Nature's chief of} correspondents for America.

1. Stern, R. J. Geology 33, 557-560 (2005).

2. Cawood, P. A., Kröner A., Pisarevsky, S. GSA Today 16, 4-11 (2006)

3. Davies, G. F. Earth Planet. Sci. Lett. 243, 376-382 (2006).

4. Kusky, T. M., Li, J-H. \& Tucker, R. D. Science 292, 1142-1145 (2001).

5. Harrison, T. M. et al. Science 310, 1947-1950 (2005)

6. Valley, J. W. et al Science 312,1139a (2006).

7. Smithies, R. H. et al. Gondwana Res. (in the press).

8. Brown, M. Geology (in the press).

9. Bédard, J. Geochim. Cosmochim. Acta 70, 1188-1214 (2006). 